九州大学学術情報リポジトリ

Kyushu University Institutional Repository

\title{
Turbulent Structure in a Closed Density Stratified Water Body with Floating Vegetation
}

Ozaki, Akinori

Faculty of Agriculture Kyushu University

Hamagami, Kunihiko

Graduate School of Bioresource and Bioenvironmental Sciences, Kyushu University

Mori, Ken

Faculty of Agriculture Kyushu University

Hirai, Yasumaru

Faculty of Agriculture Kyushu University

https://doi.org/10.5109/9300

出版情報：九州大学大学院農学研究院紀要. 52 (1)，pp.163-169，2007-02-28. Faculty of Agriculture, Kyushu University

バージョン：

権利関係 : 


\title{
Turbulent Structure in a Closed Density Stratified Water Body with Floating Vegetation
}

\author{
Akinori OZAKI ${ }^{1}$, Kunihiko HAMAGAMI ${ }^{2}$, Ken MORI ${ }^{3 *}$ \\ and Yasumaru HIRAI ${ }^{3}$
}

\author{
Laboratory of Bioproduction and Environment Information Sciences, Division of Bioproduction and \\ Environment Information Sciences, Department of Bioproduction and Environmental Science, \\ Faculty of Agriculture, Kyushu University, Fukuoka 812-8581, Japan \\ (Received November 10, 2006 and accepted December 1, 2006)
}

\begin{abstract}
A contributing factor on a water quality issue in a closed water body is in a sedimentation and a deposition of pollutants due to a domination of flow stagnation. Therefore, with regard to the preservation and improvement of the water quality in the water body, it is important to understand the response of the fluid to thermal and mechanical turbulences. Furthermore, when we consider the use of floating vegetation as a purification technique to improve the water quality, it is also important to elucidate the effect of the luxuriant growth of floating vegetation on the properties of the fluid. In the present study, in order to elucidate the wind-induced fluid movement in a closed water body where floating vegetation luxuriant growth on water surface, we conducted hydraulic experiments on density stratification with wind-induced flow using wind tunnel test tank and we experimentally considered the effect of coverage of floating vegetation on fluid movement that is induced by wind action on the water surface. The results indicated that the production of turbulent energy was controled by luxuriant growth of floating vegetation on the water surface and the energy used for the mixture between upper and lower layers at the density interface was decreased. This mechanism could be explained by using the concept of turbulent energy balance.
\end{abstract}

\section{INTRODUCTION}

In a closed water body, fluid is generally stratified by its vertical density difference (temperature, nutrient salts, etc.). These density differences arise due to the limited inflow and outflow in the water body. In the absence of disturbance in the water body, the vertical density stratification is stabilized. The behavior of a substance in the water body is influenced by the mechanical disturbance (wind-induced flow) and the thermal disturbance (convective flow). With the action of the wind on the surface of such the water body, the surface layer becomes turbulent due to the wind-induced flow. Such wind action on the water body with density stratification gives rise to the entrainment phenomenon at the density interface. This phenomenon, which results from the mixture between the upper and lower water layers, affects the water quality in the water body. When there are little disturbances in the water body, the driving force of flow in the water body is

\footnotetext{
1 Laboratory of Bioproduction and Environmental Information Sciences, Division of Bioproduction and Environment Sciences, Department of Bioproduction Environmental Sciences, Faculty of Agriculture Kyushu University, JSPS Researcher

2 Laboratory of Bioproduction and Environmental Information Sciences, Division of Bioproduction and Environment Sciences, Department of Bioproduction Environmental Sciences, Graduate School of Bioresource and Bioenvironmental Sciences Kyushu University

3 Laboratory of Bioproduction and Environmental Information Sciences, Division of Bioproduction and Environment Sciences, Department of Bioproduction Environmental Sciences, Faculty of Agriculture Kyushu University

* Corresponding author* (E-mail moriken@bpes.kyushu-u. ac.jp)
}

absent and water quality deteriorates. Therefore, when we address the water quality problem in a closed water body, it is very important to clarify the characteristics of fluid flow based on disturbances.

By the way, water quality problems associated with closed water bodies, including eutrophication, have been studied, and water purification with floating vegetation has been proposed for several water bodies (Masushima 2001, Oki 2001, Tai 2001). The purification ability of floating vegetation is due to a filter effect with regard to suspended solids and an absorption effect with regard to nutrient salts. These abilities are attained when the floating vegetation is eliminated outside the water body (Fujita et al., 2000, Menya et al., 2001). Therefore, in order to enable water purification with floating vegetation, the suitable management of floating vegetation is required. In addition, floating vegetation does not absorb nutrient salts directly, it absorbs inorganic nutrients such as phosphorus that are mineralized by microbes at the bottom of the water body (Michioku et al., 1999, Fujita et al., 2000). Therefore, in order to utilize floating vegetation for purifying the water body, a certain amount of flow is required. However, as mentioned above, in the water body, the flow tends to stagnate and the fluids are generally stratified due to vertical density differences; thus, maintaining water quality becomes problematic. In the water body, wind-induced flow and convective flow may be induced by mechanical and thermal disturbances, respectively. When floating vegetation grows on the water surface, the flow is affected by its luxuriant growth; therefore, it is very important to clarify the relationship between its luxuriant growth and fluid movement in the water body.

With regard to the relation between flow in a closed water body and luxuriant growth of a floating vege- 
tation, the authors (2003) considered the relation between the scales of entrainment rate and the occupation rate of floating vegetation and clarified that the scales of entrainment rate was decreased with increases of occupation rate of floating vegetation. And they mentioned that entrainment phenomenon is closely related with turbulent structure near the density interface.

In the present study in order to clarify these relations in detail, we simultaneously measured the velocity and density fluctuation by using wind tunnel test tank, and we comprehended the variation of turbulent structure of the upper layerl. Finally we quantitatively evalu-

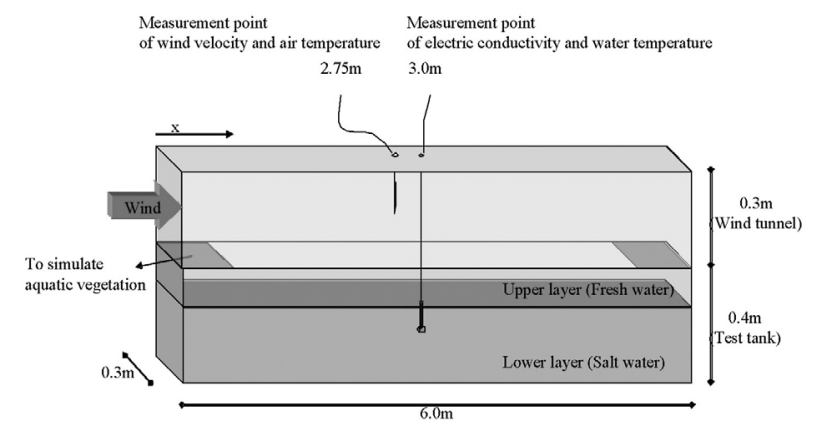

Fig. 1. Schematic diagram of experimental apparatus for entrainment phenomena. ated the turbulent structure of the upper layer for the various conditions of floating vegetation.

\section{METHODS AND DATA}

\section{Hydraulic experiment on entrainment phenome- non}

The test tank was made of acrylic plate (length $=6 \mathrm{~m}$, width $=0.3 \mathrm{~m}$, depth $=0.4 \mathrm{~m}$ ). The wind tunnel consisted of a piece of block-board on the test tank (length $=6 \mathrm{~m}$, width $=0.3 \mathrm{~m}$, depth $=0.3 \mathrm{~m})$ (cf. Fig. 1$)$. A two-layered stratified density flow was created in the

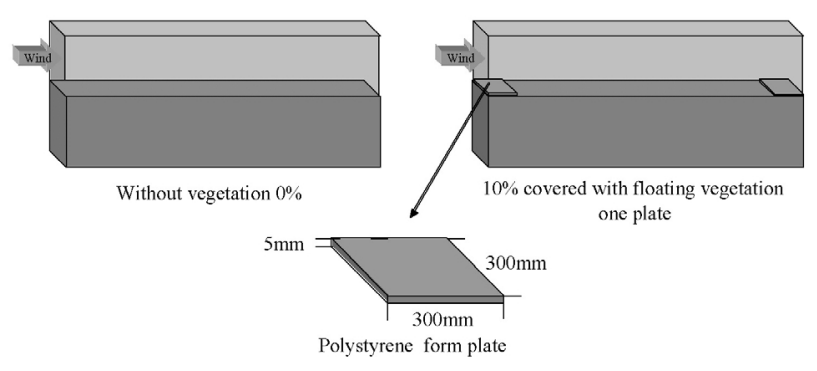

Fig. 2. Method used to simulate floating vegetation.

Table 1. Experimental conditions for entrainment phenomenon

\begin{tabular}{|c|c|c|c|c|c|c|c|}
\hline Run No. & $\begin{array}{l}\text { Vegetation } \\
\text { conditions }\end{array}$ & $\begin{array}{l}\text { Wind } \\
(\mathrm{m} / \mathrm{s})\end{array}$ & $\begin{array}{c}\Delta \rho_{0} \times 10^{3} \\
\left(\mathrm{~kg} / \mathrm{m}^{3}\right)\end{array}$ & $\begin{array}{c}\rho_{\mathrm{a}} \\
\left(\mathrm{kg} / \mathrm{m}^{3}\right)\end{array}$ & $\mathrm{h}_{10}(\mathrm{~m})$ & $\mathrm{U}_{*_{\mathrm{a}}}(\mathrm{m} / \mathrm{s})$ & $\mathrm{R}_{\mathrm{ia}}$ \\
\hline $\mathrm{I}-1$ & $0 \%$ & 5.9 & 0.0052 & 1.168 & 0.100 & 0.282 & 54.3 \\
\hline $\mathrm{I}-2$ & "I & 6.3 & 0.0018 & 1.169 & 0.116 & 0.307 & 18.3 \\
\hline $\mathrm{I}-3$ & " & 7.9 & 0.0045 & 1.171 & 0.120 & 0.407 & 27.0 \\
\hline $\mathrm{I}-4$ & " & 6.2 & 0.0043 & 1.208 & 0.104 & 0.301 & 40.0 \\
\hline $\mathrm{I}-5$ & " & 7.6 & 0.0062 & 1.226 & 0.108 & 0.388 & 35.6 \\
\hline $\mathrm{I}-6$ & "I & 8.8 & 0.0081 & 1.238 & 0.110 & 0.463 & 32.7 \\
\hline $\mathrm{I}-7$ & $10 \%$ & 6.2 & 0.0027 & 1.173 & 0.106 & 0.272 & 1.1 \\
\hline $\mathrm{I}-8$ & " & 7.2 & 0.0018 & 1.181 & 0.110 & 0.312 & 25.4 \\
\hline I-9 & " & 6.0 & 0.0013 & 1.168 & 0.100 & 0.261 & 21.1 \\
\hline I-10 & " & 8.3 & 0.0076 & 1.173 & 0.116 & 0.432 & 39.6 \\
\hline I-11 & " & 6.8 & 0.0057 & 1.173 & 0.090 & 0.301 & 47.6 \\
\hline I-12 & " & 7.4 & 0.0049 & 1.175 & 0.110 & 0.376 & 32.3 \\
\hline $\mathrm{I}-13$ & " & 7.7 & 0.0021 & 1.198 & 0.158 & 0.395 & 17.6 \\
\hline I-14 & " & 7.9 & 0.0112 & 1.196 & 0.101 & 0.407 & 55.9 \\
\hline I-15 & "I & 7.8 & 0.0107 & 1.195 & 0.084 & 0.401 & 45.8 \\
\hline I-16 & $20 \%$ & 6.0 & 0.0076 & 1.190 & 0.100 & 0.261 & 90.1 \\
\hline $\mathrm{I}-17$ & " & 6.0 & 0.0059 & 1.190 & 0.110 & 0.261 & 80.9 \\
\hline I-18 & " & 6.0 & 0.0028 & 1.176 & 0.104 & 0.261 & 41.2 \\
\hline I-19 & " & 7.5 & 0.0080 & 1.183 & 0.107 & 0.488 & 48.8 \\
\hline $\mathrm{I}-20$ & " & 8.1 & 0.0047 & 1.190 & 0.109 & 0.244 & 24.4 \\
\hline I-21 & " & 7.9 & 0.0037 & 1.173 & 0.115 & 0.217 & 21.7 \\
\hline I-22 & " & 7.7 & 0.0027 & 1.194 & 0.141 & 0.201 & 20.1 \\
\hline I-23 & " & 7.8 & 0.0020 & 1.192 & 0.113 & 0.401 & 12.1 \\
\hline I-24 & " & 5.2 & 0.0081 & 1.197 & 0.094 & 0.232 & 116.5 \\
\hline I-25 & " & 5.5 & 0.0058 & 1.203 & 0.108 & 0.257 & 77.4 \\
\hline I-26 & $30 \%$ & 5.9 & 0.0058 & 1.188 & 0.101 & 0.258 & 68.4 \\
\hline $\mathrm{I}-27$ & " & 6.4 & 0.0033 & 1.189 & 0.108 & 0.265 & 35.1 \\
\hline I-28 & " & 5.9 & 0.0027 & 1.173 & 0.102 & 0.258 & 32.9 \\
\hline $\mathrm{I}-29$ & "I & 7.5 & 0.0059 & 1.194 & 0.094 & 0.382 & 31.4 \\
\hline $\mathrm{I}-30$ & " & 7.7 & 0.0053 & 1.208 & 0.100 & 0.395 & 27.9 \\
\hline $\mathrm{I}-31$ & " & 8.1 & 0.0037 & 1.202 & 0.100 & 0.419 & 16.9 \\
\hline I-32 & " & 7.9 & 0.0028 & 1.197 & 0.110 & 0.408 & 15.3 \\
\hline
\end{tabular}


test tank. The upper layer comprised fresh water, while the lower layer comprised salt water. In order to avoid an impulsive break down of the density interface, the blowing power was gradually increased up to the specified wind velocity. The measured parameters were the wind velocity, water temperature and salinity. The wind velocity was measured with a hot-wire velocimetry at height $0.15 \mathrm{~m}$ from water surface; salinity, with a conductance meter; and water temperature, with a thermocouple. Wind velocity was measured at $2.75 \mathrm{~m}$ from the windward end, while those of salinity and water temperature were measured $3 \mathrm{~m}$ from same end. The experimental conditions are shown in Table 1 . The parameter $R_{i a}$ in this table signifies the overall Richardson number $R_{i a}=\Delta \rho_{0} g h_{10} / \rho_{a} U_{*_{a}}^{2}$, where $\Delta \rho_{0}$ is the initial density difference between the upper and lower layer; $h_{10}$, initial water depth of the upper layer; $U_{* a}$, the air friction velocity; and $g$, the gravitational acceleration. In addition, the wind velocity is defined as $0.15 \mathrm{~m}$ above water surface and $U_{*_{a}}$ is defined by use of distribution of surface wind complying with logarithmic low. Hence we obtain

$$
U(z) / U_{*_{a}}=(1 / \kappa) \ln \left(z / z_{0}\right)
$$

where $U(z)$ is the wind velocity at height $z ; z$, the height from the water surface; $\boldsymbol{\kappa}$, the Karman constant; and $z_{0}$ is the roughness parameter.

With regard to the setting conditions of floating vegetation, instead of using actual floating vegetation we used imitated vegetation made from polystyrene foam plates. The sections of the plate had a thickness of $5 \mathrm{~mm}$. Actual floating vegetation have surface roughness and root in the water, however, in order to investigate only the float effect of vegetation on the wind action, we dared to use the polystyrene form plates without surface roughness and root. Differences in the setting conditions of the floating vegetation are shown in Fig. 2.

\section{Experimental results for entrainment phenome- non}

Fig. 3 shows the descend rate of the density interface with time. Immediately after the start of the experiment, the descend rate of the density interface was variable. This is because the formation of circulation flows and development of internal waves did not occur. However, the descend rate was linearly proportional to time. Since a previous experiment without floating vegetation (Mori, et al. 1989) showed the same tendency, we can conclude that the descend rate of the density interface is constant expect shortly after the start of the experiment. Hence the entrainment velocity $U_{e}$ in the present experiments could also be described as

$$
U_{e} \equiv d h / d t=\text { const }
$$

Fig. 4 shows the relationship between the entrainment coefficient $E$ and the overall Richardson number $R_{i a}$. The entrainment coefficient $E$ was defined as $E=U_{e}$ $/ U_{*_{a}}$. E represents the strength of vertical mixture at the

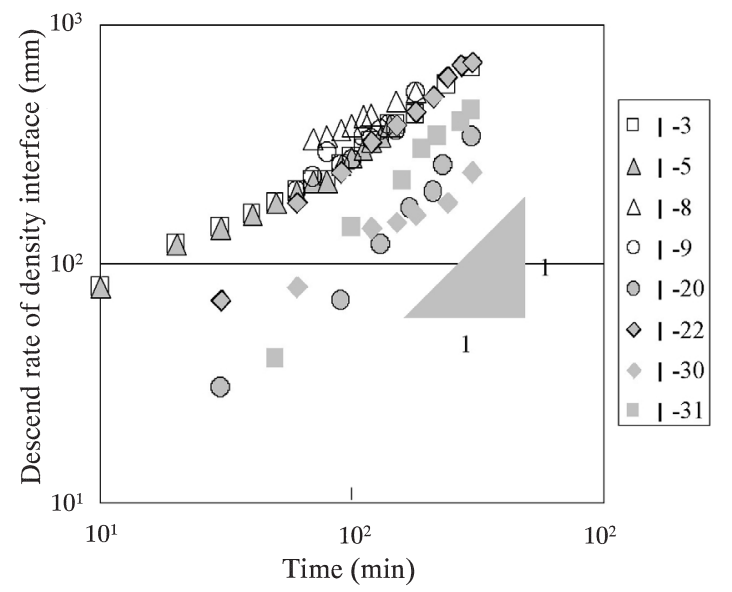

Fig. 3. Descend rate of the density interface with time for various overall Richardson numbers $R_{i a}$.

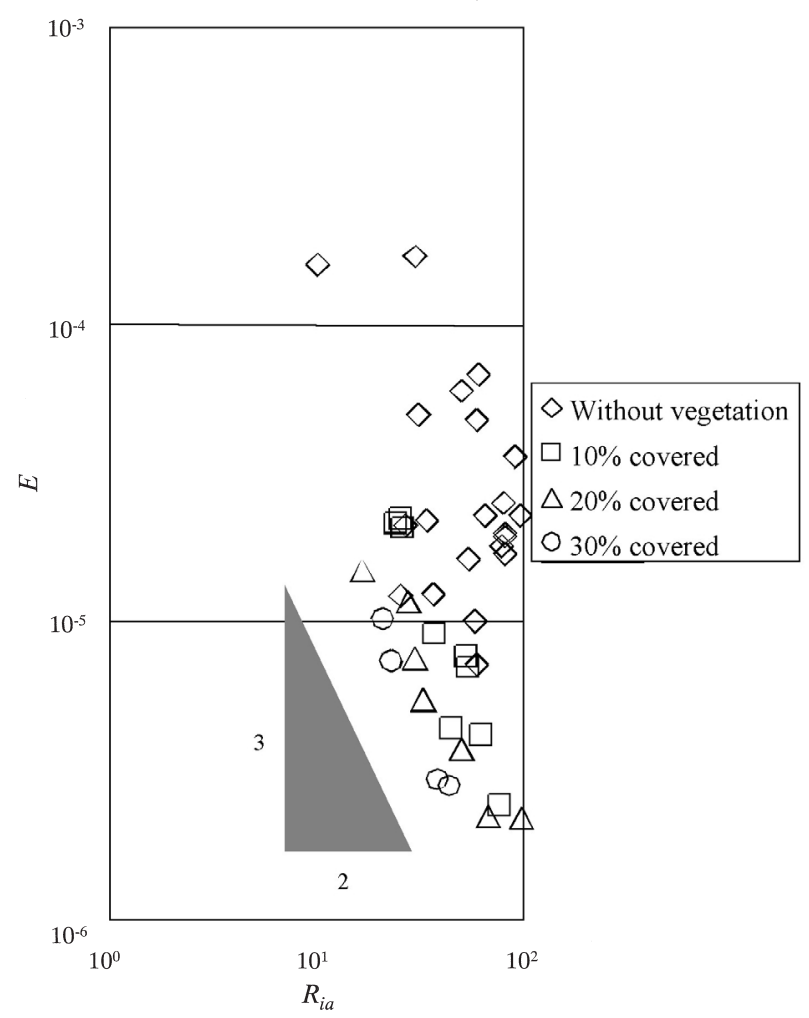

Fig. 4. Entrainment rate $E$ plotted logarithmically against overall Richardson numbers $R_{i a}$.

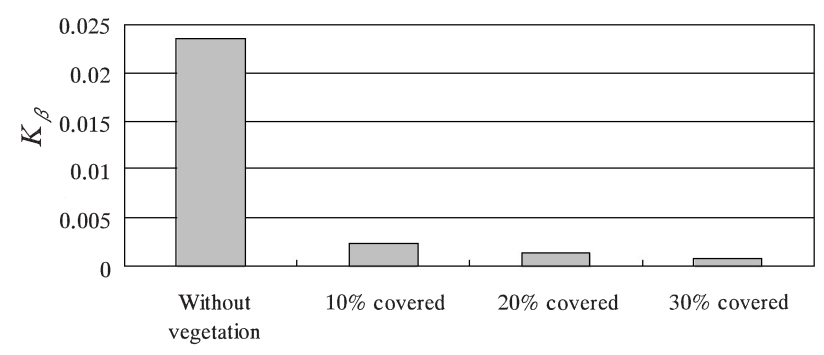

Fig. 5. $K_{\beta}$ as a function of the condition of floating vegetation. 
density interface and $R_{i a}$ represents the stability of the density stratification. In this figure, the results of experimental condition without vegetation includes the previous results of the entrainment velocity that obtained by Mori et al. (1989) and authors. (2004). Fig. 4 illustrates some interesting information.

Firstly, comparing $E$ to collinear $R_{i a}$, the entrainment coefficient values $E$ in the experiments with floating vegetation are much lower than in the experiment without floating vegetation.

Secondly, the entrainment velocity was lowered with increases of the coverage of floating vegetation.

Finally, the previous results of $E \propto R_{i a}{ }^{-3 / 2}$ for the experiment without floating vegetation are acceptable in this experiment for the values of $R_{i \alpha}$ ranging from 0 to 100.

Hence, the coefficient of proportion $K_{\beta}$ can be defined as $E=K_{\beta} R_{i a}{ }^{-3 / 2}$.

Fig. 5 shows the coefficient of proportion $K_{\beta}$. From this figure, $K_{\beta}$ tends to be exponentially lower as the coverage of floating vegetation increases.

We conjecture that the entrainment velocity in the stratified two-layered density flow is related to the turbulence structure in the neighborhood of the density interface, i.e., the amount of turbulent flow energy that is produced at the water surface and transported and diffused into the neighborhood of the density interface. Therefore, in order to clarify the variation in the coefficient proportion $K_{\beta}$, which arises from the variation in the conditions of floating vegetation, we quantitatively evaluated the turbulent structure of the upper layer for various conditions of vegetation.

\section{Hydraulic experiment on turbulent structure of the upper layer}

The equipment and methods for this experiment were the same as those employed in the experiment on the entrainment phenomenon. The measured parameters were wind velocity, water temperature, flow velocity and salinity. The wind velocity was measured with a hot-wire velocimetry; water temperature, with a thermocouple; flow velocity, with a X-type hot-wire velocimetry and salinity, with a conductance meter. Wind velocity was measured at $2.75 \mathrm{~m}$ from the windward end and at height $0.15 \mathrm{~m}$ from water surface, while those of salinity and water temperature were measured $3 \mathrm{~m}$ from windward end. Flow velocity and salinity were measured at the same height from water surface to density interface (cf. Fig. 6). Detail sampling time, frequency and vertical interval was shown in Table2.

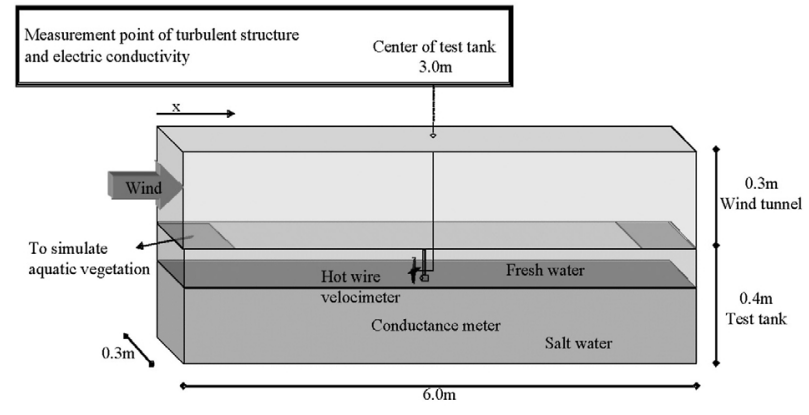

Fig. 6. Schematic diagram of experimental apparatus for turbulent structure.

Table 2. Sampling conditions of velocity fluctuation

\begin{tabular}{ccc}
\hline $\begin{array}{c}\text { Height from } \\
\text { density interface } \\
(\mathrm{mm})\end{array}$ & $\begin{array}{c}\text { Measurement } \\
\text { time } \\
(\mathrm{sec})\end{array}$ & $\begin{array}{c}\text { Measurement } \\
\text { interval } \\
(\mathrm{mm})\end{array}$ \\
\hline $0 \sim 30$ & 60 & 5 \\
$30 \sim 50$ & 25 & 5 \\
$50 \sim 100$ & 25 & 10 \\
\hline
\end{tabular}

The experimental conditions for turbulent structure are shown in Table3. In this table, $U_{*}$ is the water friction velocity.

\section{Experimental results for turbulent structure of the upper layer}

Time averaged flow velocities in the horizontal direction $\bar{U}$ and vertical direction $\bar{W}$, turbulent intensities in the horizontal direction $U^{\prime}$ and vertical direction $W^{\prime}$, and Reynolds stress $-\overline{u^{\prime} w}$ ' were calculated by using the measured data. $U^{\prime}$ and $W^{\prime}$ can be expressed as $U^{\prime}=\sqrt{\frac{1}{T} \int_{0}^{T} u^{\prime} d t}$ and $W^{\prime}=\sqrt{\frac{1}{T} \int_{0}^{T} w^{\prime} d t}$, respectively.

Where $T$ is the measurement time of velocity; $u$, velocity fluctuation in the horizontal direction; and $w^{\prime}$, velocity fluctuation in the vertical direction.

Fig. 7 shows the profiles of the time-averaged flow velocity in the horizontal direction $\bar{U}$ for the various conditions of floating vegetation. In Fig. 7, the horizontal axis represents the dimensionless time-averaged flow rate in the horizontal direction, and the vertical axis represents the dimensionless upper depth. The wind direction in these figures is from the left to right. The formula $z / h_{1}=1$ represents the water surface and $z / h_{1}=$ 0 represents the density interface. In this figures, $z$ is the measurement height and $h_{1}$ is the upper depth. With regard to the profiles of time-averaged flow veloc-

Table 3. Experimental conditions for turbulent structure

\begin{tabular}{ccccccccc}
\hline Run No. & $\begin{array}{c}\text { Vegetation } \\
\text { conditions }\end{array}$ & $\begin{array}{c}\text { Wind } \\
(\mathrm{m} / \mathrm{s})\end{array}$ & $\begin{array}{c}\Delta \rho_{0} \times 10^{3} \\
\left(\mathrm{~kg} / \mathrm{m}^{3}\right)\end{array}$ & $\begin{array}{c}\rho_{\mathrm{a}} \\
\left(\mathrm{kg} / \mathrm{m}^{3}\right)\end{array}$ & $\mathrm{h}_{10}(\mathrm{~m})$ & $\mathrm{U}_{*_{\mathrm{a}}}(\mathrm{m} / \mathrm{s})$ & $\mathrm{U}_{*}(\mathrm{~m} / \mathrm{s})$ & $\mathrm{R}_{\mathrm{ia}}$ \\
\hline II-1 & Without vegetation & 4.7 & 0.0053 & 1.256 & 0.108 & 0.207 & 0.0074 \\
II-2 & 10\% covered & 4.8 & 0.0055 & 1.261 & 0.101 & 0.214 & 0.0075 & 94.8 \\
II-3 & 20\% covered & 4.7 & 0.0054 & 1.265 & 0.111 & 0.207 & 0.0074 & 107.9 \\
II-4 & 30\% covered & 4.8 & 0.0054 & 1.294 & 0.110 & 0.214 & 0.0077 & 97.8 \\
\hline
\end{tabular}


ity in the horizontal direction $\bar{U}$, the previous study (Hino et al. 1984, Mori et al. 1989) reported that these profiles at the center of test tank was composed of three kinds of current; a wind-driven current that was a shearing layer occupied 30\% 40\% of upper depth from water surface, a return current that was a diffusing layer in which the velocity was near uniformity and an entrainment layer that occupied about $20 \%$ of the upper of the density interface. The flow velocity near the density interface was about zero. These currents were unique to wind-induced flow in a density-stratified water body. In the present experiments, which simulated luxuriant growth of floating vegetation, it was verified that a surface shearing layer, diffusing layer, and entrainment layer exist at the almost same rate as the previous studies. From the present results, the turning point from the wind-driven current to the return current moved toward the water surface with increases in the coverage ratio of floating vegetation. In addition, $\bar{U}$ at each measured point tended to decrease, with increases in the coverage ratio of floating vegetation, and the turning point from the wind-driven current to the return current moved toward the water surface with increases in the coverage ratio of floating vegetation. Therefore, as the coverage ratio of floating vegetation became large, the entrainment velocity decreased.

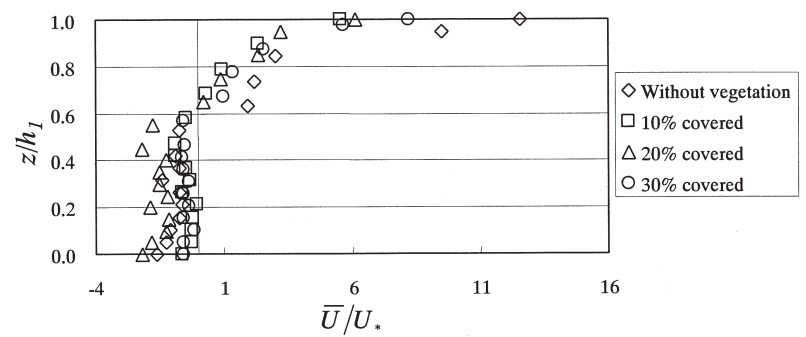

Fig. 7. Profiles of time-averaged velocity in the horizontal direction.

Fig. 8 shows the profiles of time-averaged flow velocity in the vertical direction $\bar{W}$ for the various conditions of floating vegetation. In this figure the horizontal axis represents the dimensionless time-averaged flow rate in the vertical direction, and the vertical axis represents the dimensionless upper depth. The vertical flow velocity defines the upward flow that goes from the density interface to the water surface as positive. From this figure, because the flow is impacted by the wind

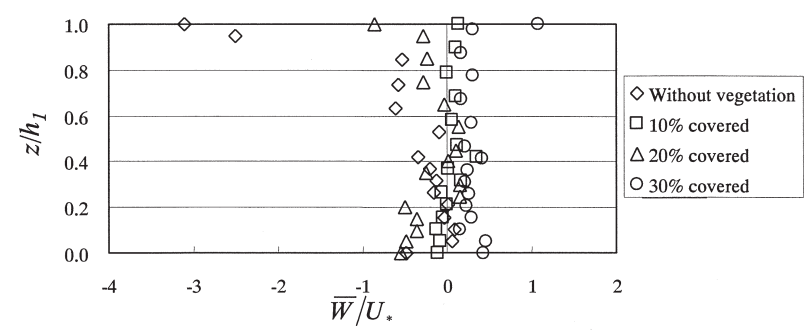

Fig. 8. Profiles of time-averaged velocity in the vertical direction. action, $\bar{W}$ was high value in depth of $20 \sim 30 \%$ from water surface. On the contrary $\bar{W}$ became almost zero uniformly under the position of about $50 \%$ of the upper depth. The time-averaged flow velocity in the vertical direction did not show a systematic difference under the various conditions of floating vegetation. This reason was considered that the sampling time was different in the vertical direction, and $\bar{W}$ was impacted by the eddy that generated intermittent in the vertical direction.

Fig. 9 shows the profiles of the turbulent intensity in the horizontal direction $U^{\prime}$. In this figure the horizontal axis represents the dimensionless turbulent intensity in the horizontal direction, and the vertical axis represents the dimensionless upper depth. The values of turbulent intensity in the horizontal direction were the largest near the water surface and decreased to an almost uniform velocity at around 30\% of the upper depth. And the horizontal turbulent intensity tended to decrease with increases in the coverage of floating vegetation at each measurement point.

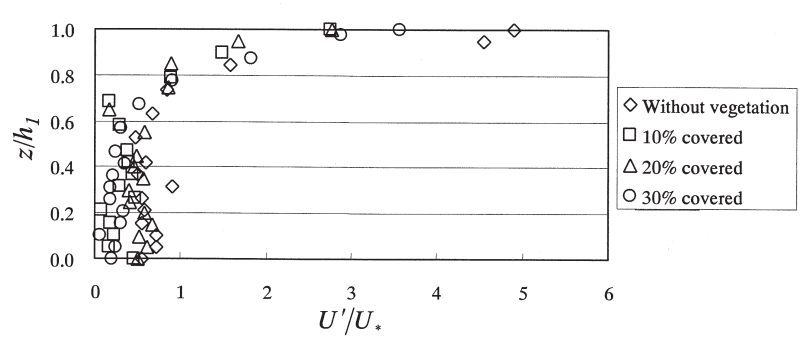

Fig. 9. Profiles of turbulent intensity in the horizontal direction.

Fig. 10 shows the profiles turbulent intensity in the vertical direction. In this figure, the horizontal axis represents the dimensionless time-averaged turbulent intensity in the vertical direction, and the vertical axis represents the dimensionless upper depth. The turbulent intensity in the vertical direction was also the largest near the water surface, and decreased to the almost uniform velocity about $30 \%$ of the upper depth.

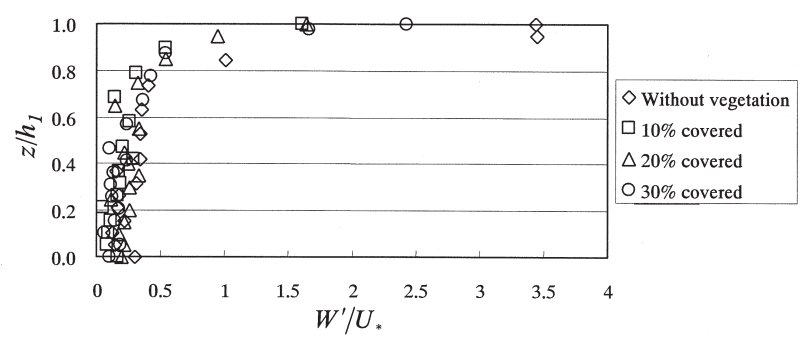

Fig. 10. Profiles of turbulent intensity in the vertical direction.

Fig. 11 shows the profiles of the Reynolds stress for the upper layer, where the Reynolds stress $-\overline{u ' w}$ ' is an index of the source of turbulent energy. In Fig. 11, the horizontal axis represents the dimensionless Reynolds stress rate, and the vertical axis represents the dimen- 
sionless upper water depth. This figure shows that the value was large only near the water surface and it became 0 mostly at around $20 \%$ of the upper water depth. There are some outstanding values in the neighborhood of the water surface. Based on these results, we concluded that the turbulent energy was produced at the water surface and transported toward the density interface.

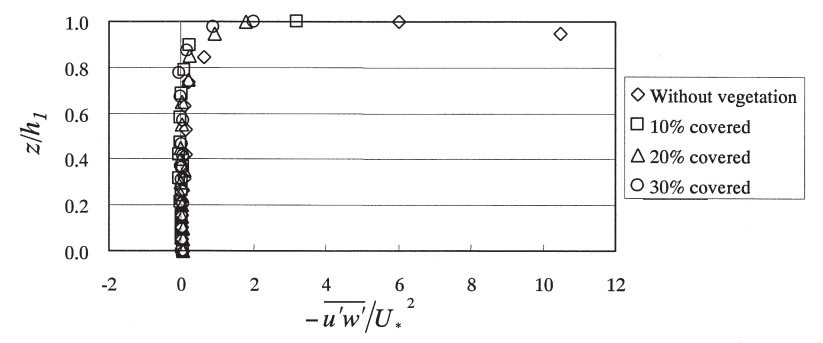

Fig. 11. Reynolds stress profiles.

\section{Turbulent energy balance}

The upper layer turbulent energy in the density stratified water body is given by the shearing force of the wind which acts on the water surface. And this energy is consumed by the diffusion transportation and viscosity dissipation. In this process, the energy which can acts on the density interface give rise to entrainment phenomenon. Here, the impacts of floating vegetation on turbulent energy balance of the upper layer is clarified theoretically by investigate the energy balance quantitatively.

\section{Turbulent energy balance equation}

Fig. 12 shows the upper layer structure in the density stratified flow. In this figure, $x$ is the mainstream direction; $z$, vertical direction; $U$, flow velocity in the horizontal direction; and $W$, flow velocity in the vertical direction; and $\rho$, density. When the upper layer structure assumed one-dimensional vertical flow, the equation of turbulent energy balance can be drawn as follow.

$$
\begin{aligned}
\frac{D \bar{e}}{D t}= & -\overline{u^{\prime} w^{\prime}} \frac{\partial \bar{U}}{\partial z}-\frac{\partial}{\partial z}\left(\overline{e W+\frac{P^{\prime} w^{\prime}}{\rho_{r}}}\right) \\
& -\frac{g}{\rho_{r}} \overline{\rho^{\prime} w^{\prime}}+v\left(\overline{u^{\prime} \Delta u}, \overline{w^{\prime} \Delta w^{\prime}}\right) .
\end{aligned}
$$

Where, $\rho_{r}$ is reference density; $P$, pressure; $t$, time; $v$, coefficient of viscosity and $e=\left(\bar{u}^{\prime 2}+\bar{w}^{\prime 2}\right) / 2$. In addition, ( ) means the time-averaged component and (') means the turbulent component. In the Eq. (2) first term in right-hand side represents the production of turbulent energy, second term represents energy transportation of turbulent energy due to velocity variation and pressure variation, third term represents the turbulent energy transportation due to buoyancy, and fourth term represents turbulent energy dispersion due to viscosity (Mori et al. 1989).

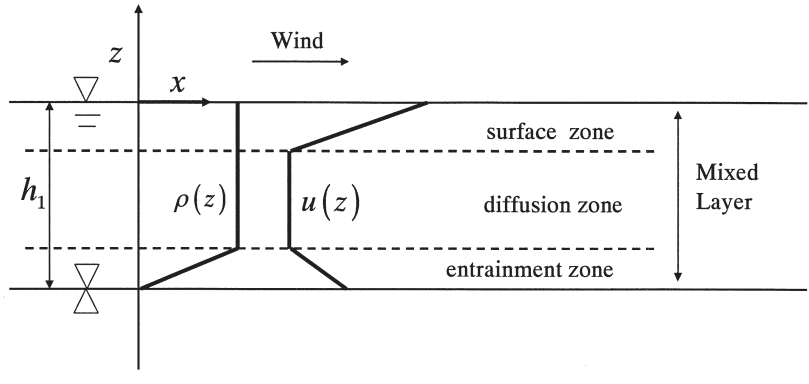

Fig. 12. The upper layer structure in the density stratified flow.

\section{Consideration of turbulent energy balance}

In the present study, we calculated the turbulent energy balance of the upper layer in density stratified flow based on the theoretical equation (2) by using the experimental results. In the Eq. (2), we assumed flow in the test tank as the isotopic turbulent flow and fourth term in right-hand side defined as $7.5 v \overline{\left(\frac{\partial U}{\partial z}\right)^{2}}$ (Turner. 1973). In addition, we assumed that the second term in right-hand side did not change with time and calculated this term by residual in right-hand side. Figs. 13 show the turbulent energy balance in the upper layer in the experimental case without vegetation (a) and experimental case with 30\% covered with floating vegetation. In this figure, $z / h_{1}=1$ represents the water surface and $z / h_{1}=0$ represents the density interface. In addition, $e_{i}$ represents the value of turbulent energy in the right-hand side term of Eq. (2), and the suffix $i$ corresponds the right-hand sides terms of Eq. (2) respectively. i.e. $i=1$ represents production term; $i=2$, transportation term; $i=3$, buoyancy term; and $i=4$, dispersion term. From these figures, the production of

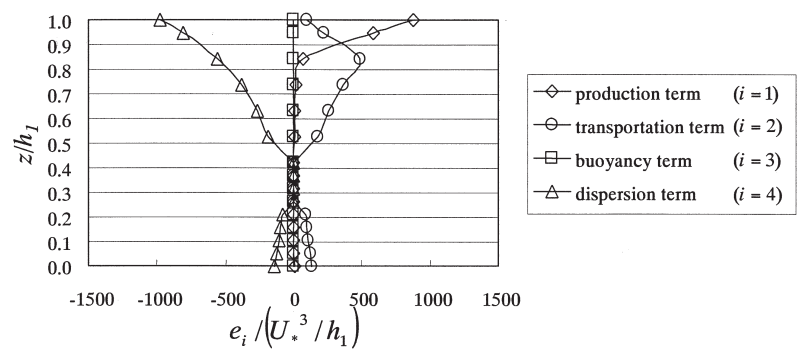

(a) Experimental case without vegetation

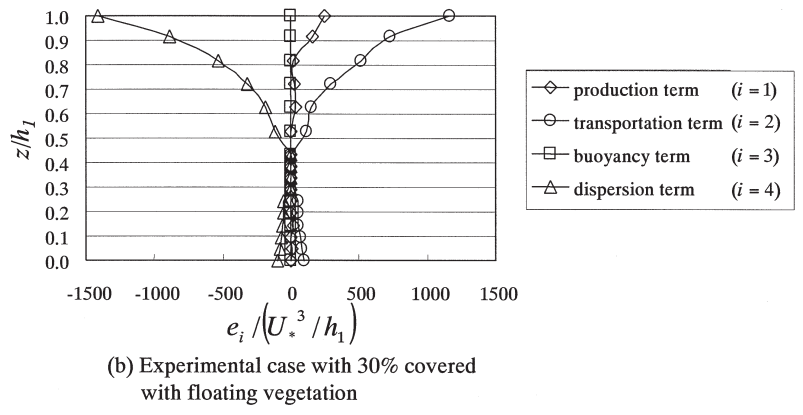

Fig. 13. Turbulent energy balance in the upper layer. 
turbulent energy was the maximum value at water surface and this value was decreased in the experimental case with 30\% covered with floating vegetation compared without vegetation. Similarly, turbulent energy dispersion due to viscosity was large value at the water surface and density interface. The turbulent energy transportation due to buoyancy had a very small value compared with other components term. This reason was considered that the two-layered stratified flow was stable and there were little impact of buoyancy.

Fig.14 shows the turbulent energy transportation due to buoyancy near the density interface. From this figure, this value was decreased with increases of the coverage of floating vegetation. This is because the energy which was used for conversion of potential energy was decreased with increased of the coverage of floating vegetation. And A similar tendency was observed for $K_{\beta}$, which denotes vertical mixing capability. These results indicated that the effect of floating vegetation on the wind-induced entrainment phenomenon could be expressed by using turbulent energy balance.

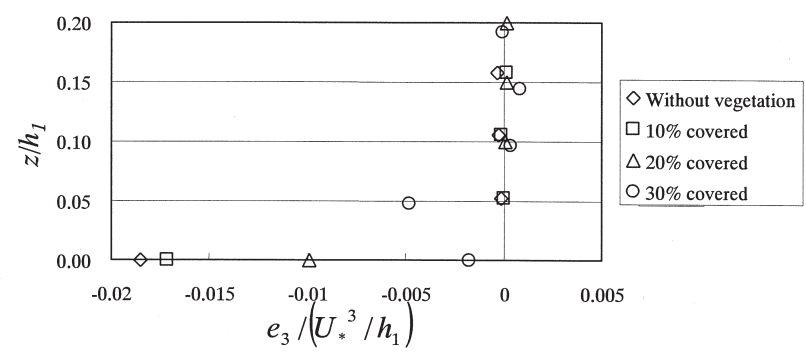

Fig. 14. Buoyancy term near the density interface for various conditions of floating vegetation.

\section{CONCLUSION}

In the present study, in order to elucidate the fluid motion by wind-induced flow in closed water body where floating vegetation luxuriant growth on water surface, we conducted hydraulic experiment with regard to density stratification with wind-induced flow using wind tunnel test tank and we experimentally considered the effect of coverage of floating vegetation on wind-induced flow in closed water body. The general conclusion can be drawn as follow.

1. From the experimental result of entrainment phenomenon, the entrainment velocity at density interface was decreased with increases of coverage of floating vegetation. This reason was explained that the shearing stress of the wind was lower in the growth of floating vegetation than in their absence at water surface.

2. From the experimental results of turbulent structure, the luxuriant growth of floating vegetation changes the turning point of flow from the wind-driven current to the return current. Decreases in the wind-driven current deadened the energy of the return current and the entrainment region was decreased. And turbulent intensity and Reynolds stress were also decreased with increases of coverage of floating vegetation. From these findings it was considered that the amount of turbulent energy transported from the water surface toward the density interface was reduced as the coverage increased.

3. From the consideration of turbulent energy balance, turbulent structure of the upper layer in the density stratified flow could be understood in detail. And it was also clarified that when the floating vegetation grow on the water surface the production of turbulent energy and turbulent energy dispersion due to viscosity were decreased at water surface and the turbulent energy transportation due to buoyancy was also decrease at density interface compared without floating vegetation.

\section{REFERENCES}

Fujita M, Ike M, Kawagoshi Y, Miyata N 2000 Biotreatment of Persistent Substances Using Effective Microorganisms. Water Science Technology. 42, pp. 93-106

Hino M, Nadaoka K, Sumi T 1984 Turbulent Structure and Interfacial Fluctuations of Wind-Driven Two-Layered Stratified Flows. Proceedings of the Japanese Conference on Hydraulics (In Japanese). 28, pp. 239-244

Komatsu T, Umenaga S, Awaya Y 1987 Turbulent Entrainment in Stratified Shearing Flows (In Japanese). Proceedings of the Japanese Conference on Hydraulics. 31, pp. 467-472

Masushima H 2001 Water Quality Purification Using Aquatic Plants (In Japanese). Research of Soil and Field. 33, pp. $3-7$

Menya S, Ishigaki T, Mori K, Ike M, Fujita M 2001 Construction of the Database System of Water Area Direct Purification. Environmental Engineering Research. 37, pp. 247-258

Michioku K, Yasuda A, Matsushita K, Takahashi T 1999 Accumulation of Heat and Nutrients in a Reservoir Bottom Due to Heat-Salt Convection (In Japanese with English Abstract). Annual Journal of Hydraulic Engineering. 43, pp. 1055-1059

Mori K, Tohara Y, Shikasyo S, Hiramatsu K, Kato O, Cho H 1989 Turbulent Structure of Wind Induced Two-Layer Flow (In Japanese with English Abstract). Transaction of the Japanese Society of Irrigation, Drainage and Reclamation Engineering. 144, pp. 75-84

Oki Y 2001 Evaluation of the Water Quality Purification Ability of an Aquatic Plant (In Japanese). Research of Soil and Field. 33, pp. 8-14

Ozaki A, Mori K, Inoue E, Haraguchi T 2004 Impact of Aquatic Plants on Entrainment Phenomena Based on Wind-Induced Flow in a Closed Density Stratified Water Area. Journal of the International Society of Paddy and Water Environment Engineering. 2, pp. 125-134

Tai H 2001 Approach of Water Quality Purification Using Aquatic Vegetation (In Japanese). Research of Soil and Field. 33, pp. 21-25

Turner, J. S 1973 Buoyancy effects in fluids. Cambridge University Press

Ura M, Hirohata K 1984 Turbulent Structure and Entrainment Phenomena of Wind-Induced

Two-Layered Flow (In Japanese). Proceedings of Coastal Engineering. 31, pp. 650-654

Ura M 1985 Contribution of the Turbulence to Entrainment across a Density Interface (In Japanese). Proceedings of the Japanese Conference on Hydraulics. 29, pp. 401-406 